\title{
Anticancer Activity of Silver Nan Particles against Cell Line MCF-7-Human - Breast Cancer through MTT Assay
}

\author{
C. K. Senthilkumaran ${ }^{1 *}$ and S. Sugapriya ${ }^{2}$ \\ sks.apsc@psgtech.ac.in, sugapriya0314@gmail.com
}

${ }^{1}$ Department of Applied Science, PSG College of Technology, Coimbatore, India.,

\begin{abstract}
Silver nanoparticles were synthesized by simple chemical precipitation method demonstrated a considerable activity of anticancer against cell line MCF 7human - breast cancer at variousdoses. Above $60 \%$ of cell death has been observed in maximum concentration level of $1000 \mu \mathrm{L}$. Results showed that at higher concentration levels have significant cell mortality. After the 48 hours of incubation the inhibitory effect was observed. Consequently, 50\%onkilling the cancer cell decides the Inhibitory. Concentration I,C50of the prepared silver nanoparticles in case of cell lineMCF-7human breast cancer, holds at round $846 \mu \mathrm{L}$. In addition, the light microscopic observation of control and different concentration of silver nanoparticles sample treated cell lines MCF7 was studied.
\end{abstract}

Keywords: Silver nanoparticles, Cytotoxicity, MCF-7 and MTT assay.

\section{Introduction}

Cancer cells exhibit an uncontrolled division, which would lead to the increasing the number of dividing cells [1,2]. It is an extraordinary kind of tissue growth but due to its steady growth progress it can be a preventable disease [3]. The utilization of cultured tissues and cells has risen due to Invitro cytotoxicity testing [4]. This testing procedure reduces the use of laboratory animals [5]. Invitrocytotoxicity testing cultures can be grown under anoptimised environment like conditional temperature with proper humidity and supply of controlled oxygen, pHetc resulting to minimizing the experimental errors. Recent decade Breast cancer is the utmost frequentlypinpointingcancer for women worldwide. Cytotoxicity or Anticancer has been expounded as the tissue cell dispatch property of a chemical compound. Nowadays there is an increasing demand for anticancer therapy [6]. To measure the cytotoxic properties MTT assay has been defined as rapid and reproducible manner used to screen the cytotoxicity drugs.

The nanoparticles like $\mathrm{Ag}, \mathrm{Au}, \mathrm{ZnO}, \mathrm{TiO}_{2}, \mathrm{NiO}$ etc., have significant properties due to their cytotoxic activity [7, 8]. Nanoparticles or nanotechnology provides a more prominent and significant part in the treatment of cancer cells [9].In thisresearch work, we focused on the cytotoxicity assessment by the synthesized nanoparticles on human - breast cancer cells. Ag nanoparticles synthesized by chemical precipitation method are taken to anticancer activity. 


\section{Process With The Reagents}

\subsection{Materials}

3-(4,5-dimethylthiazol-2-yl),-2,5-diphenyl-tetrazolium. bromide, a yellow tetrazole, phosphate buffered saline (PBS), Dimethyl sulphoxide (DMSO), The cell chemical culture such as FBS - Fetal Bovine Serum and EMEM - Eagles Minimum Essential Medium from sigma Aldrich chemical.

\subsection{Cell culture}

The Michigan Cancer Foundation-MCF-7human - breast cancer cell line cultured has beenacquired out-ofNCCS - National Centre, for Cell. Science, Pune. The obtained cell was cultivate in EMEM containing $\mathrm{FBS} 10 \%$ and kept at $37^{\circ} \mathrm{C}, \mathrm{CO}_{2} 5 \%$, air $95 \%$ and with $100 \%$ relative humidity.

\subsection{Stock Solution}

Stock solution was prepared by using the prepared nano powders like Ag nanoparticles. By taking the accurate weight, one $\mathrm{mg}$ of prepared samples was dissolved with $2 \mathrm{~mL}$ of double distilled or de-ionized water.

Cytotoxicity assessment of prepared samples using MTT assay based on the perception of mitochondrial dehydrogenase venture in the living cells. The cytotoxicity of prepared silver nanoparticles on the cell line MCF-7human - breast cancer has been discussed byMTT Assay.

\section{Principle}

3-(4,5-dimethylthiazol-2-yl),-2,5-diphenyl-tetrazolium. bromide, a yellow tetrazolein phosphate buffered saline has been cleared by mitochondrial dehydrogenase of feasible cells, relenting a measurable purple colour formazan crystals product. The formed purple colour formazan crystalsproduction is inversely consistent to the degree of cytotoxicity orcorresponding to the feasible cell number.

\section{Procedure}

Concerning to make single cell suspension the monolayer cell has been detached along with trypsin-ethylenediaminetetraacetic acid (EDTA) and feasible cells have beencalculated using a hemocytometer. Then it was diluted with phosphate buffered saline5\% to providelag density $1 \times 10^{5}$ cells/mL.Concerning $100 \mu \mathrm{L}$ eachdiscabout suspension culturehas been sowedinquire 96-discsheetclose tolayeredsolidity of 10,000 disc. It has been hatched to grant in-favour-of unit loyalty at $37^{\circ} \mathrm{C}, \mathrm{CO}_{2} 5 \%$, air $95 \%$ and with $100 \%$ relative humidity. Later 24 hours $100 \mu \mathrm{L}$ of medium was treated with different dosages 50, 100, 250, 500 and $1000 \mu \mathrm{L}$ prepared Ag nanoparticles Each nanoparticles treated cells were then hatched or incubated at $37^{\circ} \mathrm{C}, \mathrm{CO}_{2} 5 \%$, air $95 \%$ and with $100 \%$ relative humidity for 48 hours. In order to get results, there were control (medium without sample) and triplicate was maintained for all the prepared concentrations.

Subsequently, the cells have been subjected for MTT assay after the cell treatment process. $100 \mu \mathrm{L}$ of MTT in phosphate buffered saline has been prepared and $15 \mu \mathrm{Lof}$ MTT was added in each prepared nanoparticle treated discalsohatchedclose to $37^{\circ} \mathrm{C}$ in-favour-of 4 hours. 
Standardalong MTT has been releasedas well as developed purple colour formazan crystals have beendispersible along $100 \mu \mathrm{L}$, Dimethyl.Sulphoxide. (DMSO) alsodevouraround 570nm over ELISA disc reciter. In-vitrocytotoxicity has been calculated at the percentage of viable cells at different concentration of sample relative to untreated (Control) cell. Optical density (OD) value has beenexposed to segregate the proportion of cell inhibition by make use ofbelowritual,

$$
\begin{aligned}
& \text { Percentage of, viability (\%). }=\frac{\text { Mean OD. value to experimental, sample. }}{\text { Mean OD. va. lue to experimental }} \times 100 \\
& \text { control. (Untreated) }
\end{aligned}
$$

Percentage of cytotoxicity $(\%)=100$, - Percentage of viability $(\%)$

Consequently, 50\%onkilling the cancer cell decides the Inhibitory. Concentration I, $\mathrm{C}_{50}$ with the use about data generated plot of dose-response curve.

\section{Microscopic Observation}

MCF-7 cells have been grown and hatched or incubated with prepared nanoparticles sample belonging to $\mathrm{IC}_{50}$ concentration, the prepared $\mathrm{Ag}$ nanoparticles treated and untreated discs have been monitored under a light microscope to identify the morphological changes and recorded as photographed.

\section{Results And Discussion}

Silver nanoparticles have synthesized by simple chemical precipitation method demonstrated a considerable cytotoxicity upon cell lines MCF-7-breast cancer at various doses. Figure 1 depicts that $62.42 \%$ of cell death was observed in maximum concentration level $(1000 \mu \mathrm{L})$ of the prepared Ag nanoparticles. More than $60 \%$ of cell death was observed in maximum concentration level of $1000 \mu \mathrm{L}$. Results showed that at higher concentration levels have significant cell mortality. The inhibitory effect has been observed later 48 hours of propagation. Table shows difference in the percentage of feasibility, cytotoxicity also inhibition with concentration of the Ag nanoparticles upon cell line MCF-7-breast cancer. Consequently, 50\% onkilling the cancer cell decides the Inhibitory. Concentration I, $\mathrm{C}_{50}$ of the prepared nanoparticles upon cell lineMCF-7-human - breast cancer, holds at round $846 \mu \mathrm{L}$ (Figure 1). In addition, the light microscopic observation of control and different concentration of $\mathrm{Ag}$ nanoparticles i.e., $50 \mu \mathrm{L}, 100 \mu \mathrm{L}, 250 \mu \mathrm{L}, 500 \mu \mathrm{L}$ and $1000 \mu \mathrm{L}$ treated cell lines MCF-7 is showed in Figure 2.

Table 1: MTT assay on Ag nanoparticles against cell line MCF-7

\begin{tabular}{|l|l|l|l|}
\hline $\begin{array}{l}\text { Concentration (Dosages) } \\
(\mu \mathrm{L})\end{array}$ & \% inhibition & $\mathrm{R}^{2}$ value & $\mathrm{IC}_{50}$ \\
\hline 50 & 9.2 & & \\
\cline { 1 - 2 } 100 & 17.34 & \multirow{2}{*}{0.982} & \multirow{2}{*}{$846 \mu \mathrm{L}$} \\
\cline { 1 - 2 } 250 & 31.32 & & \\
\hline 1000 & 43.71 & & \\
\hline
\end{tabular}




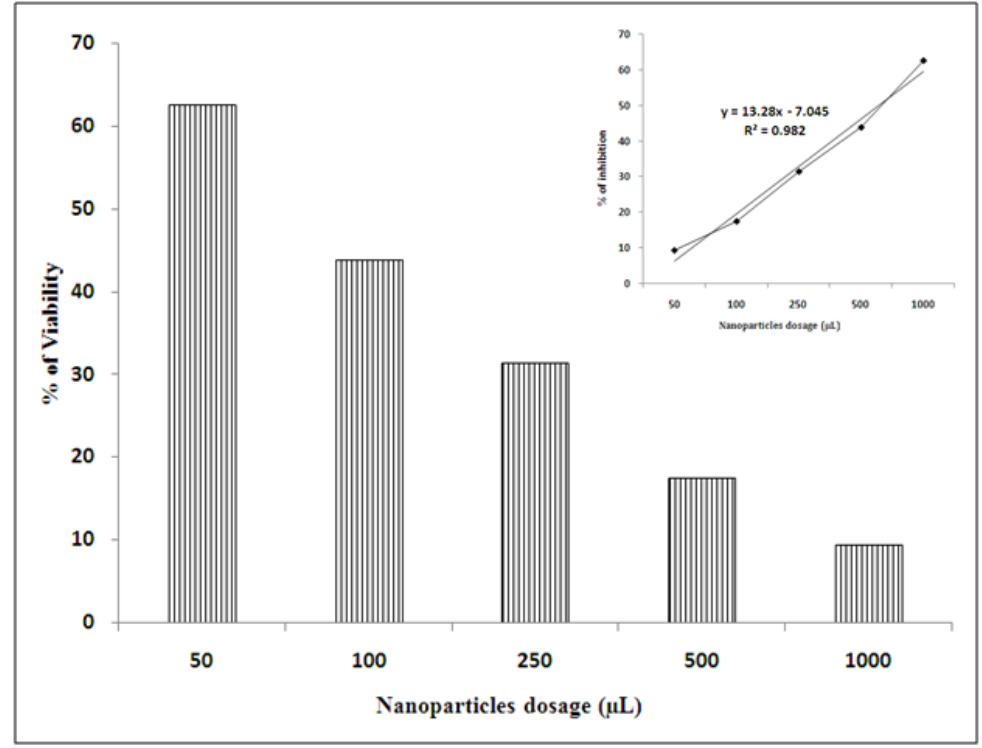

Figure 1 Cytotoxicity of Ag nanoparticles on cell line MCF-7

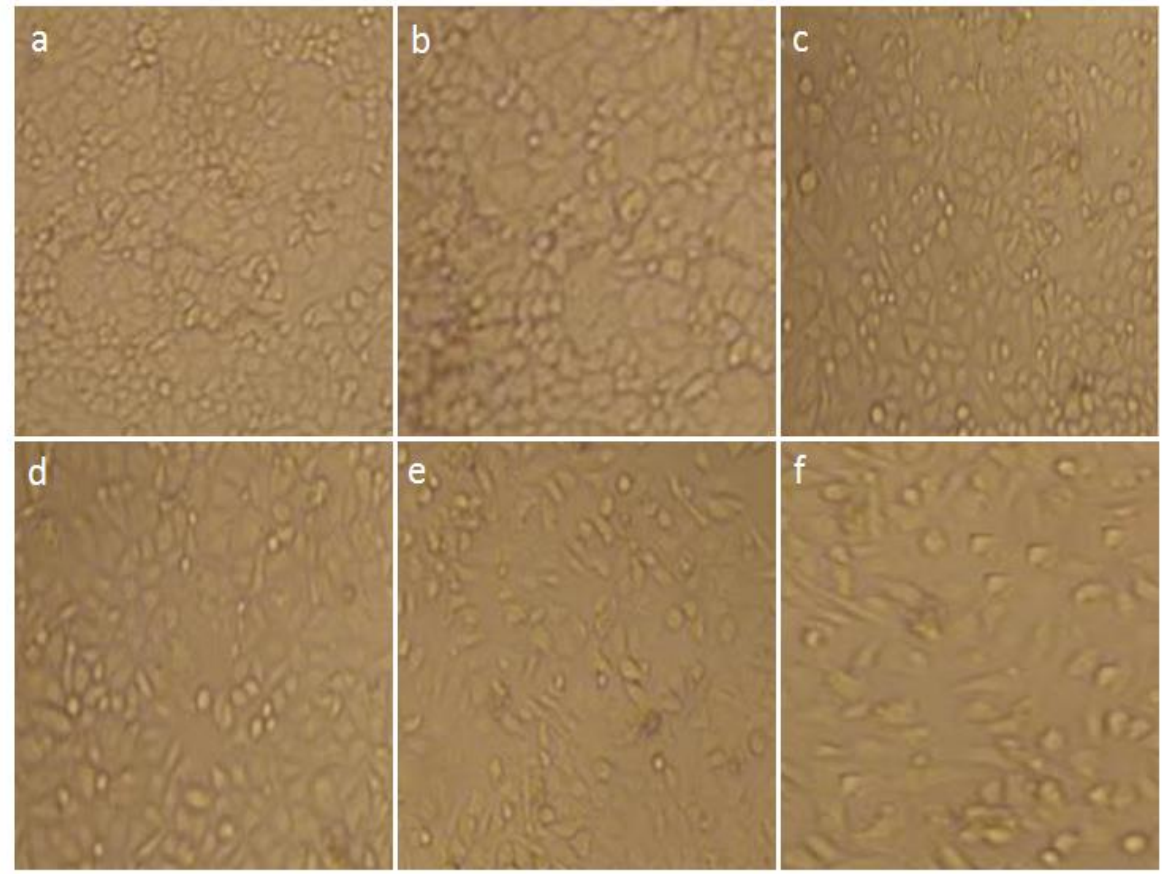

Figure 2: Morphological observation of different concentration of Ag nanoparticles treated cell line MCF-7 under light microscope.a) Control, b) $50 \mu \mathrm{L}$, e) $500 \mu \mathrm{L}$ and f) $1000 \mu \mathrm{L}$.

c) $100 \mu \mathrm{L}, \mathrm{d}) 250 \mu \mathrm{L}$, 
The silver nanoparticles have been synthesized by simple chemical precipitation method demonstrated a considerable anticancer activity upon cell lines MCF-7-human - breast cancer at various doses. Above $60 \%$ of cell death was observed in maximum concentration level of $1000 \mu \mathrm{L}$. Results showed that at higher concentration levels have significant cell mortality. After the 48 hours of incubation the inhibitory effect was observed. Consequently, $50 \%$ onkilling the cancer cell decides the Inhibitory. Concentration I, $\mathrm{C}_{50}$ of the prepared Agnanoparticles upon cell line MCF-7-human - breast cancer, holds at round $846 \mu \mathrm{L}$.

Silver nanoparticles was synthesized by chemical precipitation method shows anticancer activity or cytotoxicity on cell line MCF-7-human - breast cancer. In this report, concentration on dosage level increases with increasing the percentage of inhibition. It is due to the increase in the number of prepared samples of Silver nanoparticles. From here the percentage concerning the inhibition on cell line MCF-7- human -breast cancer depicts that at higher concentration levels has significant cell mortality. It decides the Inhibitory. Concentration I, $\mathrm{C}_{50}$ the prepared Agnanoparticles upon cell line MCF-7-human - breast cancer, holds at round $846 \mu \mathrm{L}$.

\section{Conclusion}

Silver nanoparticles was synthesized by chemical precipitation method shows anticancer activity or cytotoxicity upon cell line MCF-7-human - breast cancer. This report, concentration on dosage level increases with increasing the percentage of inhibition. It is due to the increase in the number of prepared samples of Silver nanoparticles. From this study the percentage concerning the inhibition on cell line MCF-7- human - breast cancerdepict that at higher concentration levels has significant cell mortality. It decides the Inhibitory. Concentration $\mathrm{I}_{50} \mathrm{C}_{50}$ the prepared $\mathrm{Ag}$ nanoparticles upon cell line MCF-7-human - breast cancer, holds at round $846 \mu \mathrm{L}$.

\section{References}

[1] Van der Meel, R.; Sulheim, E.; Shi, Y.; Kiessling, F.; Mulder, W.J.M.; Lammers, T. Smart cancer nanomedicine. Nat. Nanotechnol. 2019, 14, 1007-1017.

[2] Huq, M.A. Green Synthesis of Silver Nanoparticles Using Pseudoduganellaeburnea MAHUQ-39 and Their Antimicrobial Mechanisms Investigation against Drug Resistant Human Pathogens. Int. J. Mol. Sci. 2020, 21, 1510.

[3] Gali-Muhtasib, H.; Sarieddine, R.; Chouaib, R. Nanoparticles as drug delivery systems for cancer treatment: Applications in targeted therapy and personalized medicine. In Nanoparticle Drug Delivery Systems for Cancer Treatment, 1st ed.; Jenny Stanford Publishing: Boca Raton, FL, USA, 2020

[4] Karuppaiah, A.; Siram, K.; Selvaraj, D.; Ramasamy, M.; Babu, D.; Sankar, V. Synergistic and enhanced anticancer effect of a facile surface modified non-cytotoxic silver nanoparticle conjugated with gemcitabine in metastatic breast cancer cells. Mater. Today Commun. 2020, 23, 100884.

[5] Raja, G.; Jang, Y.-K.; Suh, J.-S.; Kim, H.-S.; Ahn, S.H.; Kim, T.-J. Microcellular Environmental Regulation of Silver Nanoparticles in Cancer Therapy: A Critical Review. Cancers 2020, 12, 664

[6] Palai, P.K.; Mondal, A.; Chakraborti, C.K.; Banerjee, I.; Pal, K. Green synthesized aminoPEGylated silver decorated graphenenanoplatform as a tumor-targeted controlled drug delivery system. SN Appl. Sci. 2019

[7] Ding, J.; Chen, G.L.; Chen, G.F.; Guo, M.Q. One-Pot Synthesis of Epirubicin-Capped Silver Nanoparticles and Their Anticancer Activity against Hep G2 Cells. Pharmaceutics 2019, 11, 123 
[8] Zeng, F.; Xu, D.; Zhan, C.; Liang, C.; Zhao, W.; Zhang, J.; Feng, H.; Ma, X. Surfactant-Free Synthesis of Graphene Oxide Coated Silver Nanoparticles for SERS Biosensing and Intracellular Drug Delivery. ACS Appl. Nano Mater. 2018, 1, 2748-2753.

[9] Frigerio, B.; Bizzoni, C.; Jansen, G.; Leamon, C.P.; Peters, G.J.; Low, P.S.; Matherly, L.H.; Figini, M. Folate receptors and transporters: Biological role and diagnostic/therapeutic targets in cancer and other diseases. J. Exp. Clin. Cancer Res. 2019, 38, 125. 